\title{
NECESSIDADES PRODUTIVAS E EXIGÊNCIAS DE FORMAÇÃO: A FILOSOFIA NO ENSINO MÉDIO
}

\author{
NECESIDADES PRODUCTIVAS Y EXIGENCIAS DE FORMACIÓN: LA \\ FILOSOFÍA EN LA ENSEÑANZA MEDIA
}

\author{
PRODUCTIVE NEEDS AND TRAINING REQUIREMENTS: PHILOSOPHY IN \\ HIGH SCHOOL
}

\author{
Marta Sueli de Faria SFORNI ${ }^{1}$ \\ Cleder Mariano BELIERI ${ }^{2}$
}

\begin{abstract}
RESUMO: A disciplina de Filosofia não teve presença constante no currículo da Educação Básica ao longo da história da educação brasileira. Essa inconstância foi o motivo que desencadeou a necessidade de realização de uma investigação sobre os fatores que determinam sua inclusão/exclusão no Ensino Médio Brasileiro. A pesquisa foi realizada mediante um estudo bibliográfico e documental a fim de analisar a constituição histórica da disciplina de Filosofia nesse nível de ensino. O período de delimitação da pesquisa foi do Brasil Colônia à inserção do Brasil no contexto políticoeconômico neoliberal. O estudo revelou que a oscilação da presença da Filosofia nos currículos das escolas brasileiras foi influenciada pelas necessidades do setor produtivo, conforme as exigências de formação que se gestaram no interior do sistema econômico. PALAVRAS-CHAVE: Filosofia. Ensino. Política Educacional. Currículo.
\end{abstract}

ABSTRACT: The discipline of philosophy has not been a constant presence in the basic education curriculum throughout the history of Brazilian education. This inconsistency was the reason that triggered the need to conduct an investigation into the factors that determine its inclusion/exclusion in the Brazilian High School. The survey was conducted through a bibliographic and documental research in order to analyze the historical development of the discipline of philosophy in that level of education. The time period delimitation of the research was from the Colonial Brazil period to the insertion of Brazil in the neoliberal political-economic context. The study revealed that the oscillation of the presence of philosophy in the curricula of schools in Brazil was influenced by the needs of the productive sector, as the formation requirements that were started within the economic system.

KEYWORDS: Philosophy. Education. Educational Policy. Curriculum.

RESUMEN: La asignatura de Filosofía no siempre estuvo presente en el currículo de la Educación Básica a lo largo de la historia de la educación brasileña. Esa inconstancia fue el motivo que desencadenó la necesidad de realización de una investigación sobre los factores que determinan su inclusión/exclusión en la Enseñanza

\footnotetext{
${ }^{1}$ Professora do Departamento de Teoria e Prática da Educação e do Programa de Pós-Graduação em Educação da Universidade Estadual de Maringá. Email: martasforni@uol.com.br

${ }^{2}$ Doutorando no Programa de Pós-graduação em Educação pela Universidade Estadual de Maringá e Professor de Filosofia no Ensino Médio na Rede Estadual de Ensino do Paraná. Email: bellieri@gmail.com
} 
Secundaria Brasileña. La investigación fue realizada por medio de un estudio bibliográfico y documental con el fin de analizar la constitución histórica de la asignatura Filosofía en ese nivel de enseñanza. El periodo de delimitación de la investigación fue del Brasil Colonia a la inserción de Brasil en el contexto políticoeconómico neoliberal. El estudio reveló que la oscilación de la presencia de Filosofía en los currículos de las escuelas brasileñas fue influenciada por las necesidades del sector productivo, según las exigencias de formación que se gestionaron en el interior del sistema económico.

PALABRAS CLAVE: Filosofía. Enseñanza. Política Educacional. Currículo.

\section{Introdução}

O recente retorno ${ }^{3}$ da disciplina de Filosofia aos currículos escolares da Educação Básica tem suscitado debates sobre as razões da presença e da ausência dessa área do conhecimento como componente da formação básica. Em diferentes períodos históricos esse tema provocou discussões, tanto no meio acadêmico brasileiro como no contexto da própria escola, movidas por questões referentes à política educacional, legalidade, currículo, conteúdo, forma e papel dessa disciplina na formação dos estudantes.

Não raro, considera-se que o potencial que o ensino de Filosofia tem na formação de sujeitos críticos seja a razão da sua ausência nos currículos escolares em alguns momentos históricos considerados mais conservadores do ponto de vista político. Contudo, podemos perceber que mesmo em momentos históricos, como no Brasil Colônia, em que a postura de oposição à organização político-econômica não era vista com "bons olhos", a Filosofia esteve presente como componente curricular no sistema de ensino. Tal fato refuta, portanto, a ligação automática entre a oscilação da Filosofia como componente curricular e o suposto interesse e desinteresse pela formação crítica. Isso nos permite perguntar: quais fatores têm determinado a presença e a ausência da Filosofia nos currículos escolares do Ensino Médio Brasileiro?

$\mathrm{Na}$ tentativa de chegarmos a respostas para essa questão, realizamos uma pesquisa bibliográfica e documental. Por meio dela procuramos verificar as características políticas e econômicas dos momentos em que a disciplina esteve ou não presente na matriz curricular e a perspectiva de formação assumida pela instituição

${ }^{3}$ A Lei no 11.684, de 2 de junho de 2008, alterou o Art. 36 da Lei no 9.394, de 20 de dezembro de 1996, que estabelece as diretrizes e bases da educação nacional e incluiu a Filosofia e a Sociologia como disciplinas obrigatórias em todos os anos do Ensino Médio. 
escolar em cada momento. Durante o estudo, a nossa atenção esteve dirigida à relação entre a presença/ausência da filosofia no currículo escolar e a organização políticoeconômica sob a qual a sociedade brasileira estava assentada, em diferentes períodos históricos da educação brasileira. Esses períodos, dispostos aqui de forma linear, compreendem o Brasil Colônia, a Reforma Pombalina, o período pós-guerra e o período de redemocratização do país e a inserção do Brasil no contexto político-econômico neoliberal.

\section{A Filosofia como componente curricular no Brasil Colônia}

O Brasil Colônia contou com a presença da Companhia de Jesus, que, como sabemos, tinha como um de seus objetivos conter o avanço da Reforma Protestante nas novas colônias europeias, sendo responsável pela instrução escolar dos dirigentes das colônias e pela catequização dos já "habitantes das novas terras". $\mathrm{Na}$ instrução oferecida pelos Jesuítas, a Filosofia se fazia presente. Segundo Lima (2005), a educação nesse período era regida por uma “[...] concepção de ensino-aprendizagem de Filosofia marcadamente enciclopédica, de caráter autoritário e conservador, baseada nas diretrizes da Companhia de Jesus [...] normas sistematizadas pelo Ratio Studiorum” (LIMA, 2005, p. 19-20, grifos do autor).

Por ser uma educação organizada nos moldes da Escolástica, havia um controle minucioso, de modo especial sobre os professores de Filosofia e Teologia, para que a leitura dos textos filosóficos e teológicos escolhidos para o ensino e as questões trabalhadas não suscitassem o sentimento de espírito exageradamente livre $\mathrm{e}$ comprometessem os dogmas católicos (LIMA, 2005). Caso houvesse professores com inclinação para uma atividade pedagógica que se contrapusesse a esse modelo de educação, esses deveriam ser afastados do exercício da docência.

De modo geral, cabia ao aluno acolher e memorizar o conhecimento tal como transmitido pelo professor para que pudesse ser bom súdito, recebendo, com base em uma concepção essencialista, os valores, o correto modo de agir e a mais adequada forma de ação política. Considerava-se que esse conhecimento, fundado no pensamento religioso católico/cristão, ajudaria o homem a se reencontrar com sua verdadeira essência e garantir a salvação de sua alma. Nesse contexto, o conhecimento da doutrina e dos dogmas católicos era considerado condição necessária para ser um "bom cristão". 
Apesar de apontarmos esses aspectos no ensino jesuítico, não temos a intenção de realizar um julgamento anacrônico, desmerecendo o potencial revolucionário do Ratio no que se refere a sua contribuição para a "[...] superação das práticas educativas medievais em direção à pedagogia moderna" (SAVIANI, 2005, p. 7), mas apenas destacar o caráter assumido pelo ensino de Filosofia nesse momento histórico.

No Brasil Colônia, enquanto a elite recebia uma educação erudita, os demais continuavam desprovidos do conhecimento sistematizado. No ensino de conteúdos sistematizados, reservado a um grupo favorecido economicamente, o que se esperava do aluno era que ele desenvolvesse a capacidade da memória e de repetição dos valores e normas estabelecidas socialmente, garantindo assim a permanência das condições sociais que os mantinham no poder. Severino (1986) enuncia que essa concepção sob a qual se assenta esse modelo educacional “[...] desempenha uma função ideológica: camufla as reais condições da existência social e ainda faz com que a sociedade as represente como legítimas, merecedoras de todo a assentimento" (SEVERINO, 1986, p. 70).

Esse modelo educacional acabava impedindo que outro tipo de concepção filosófica existente pudesse ser transmitido aos jovens, tentando, assim, atrofiar reflexões que não estivessem de acordo com as diretrizes vigentes. Nesse período, segundo Severino (1986), o ensino de Filosofia e das outras áreas do conhecimento estava a serviço de interesses históricos específicos da sociedade pré-capitalista.

A educação no Brasil Colônia ajudava a tornar legítima a superestrutura organizada sobre os ideais mercantilistas, formando um indivíduo que pudesse garantir a efetivação dos interesses políticos e econômicos dos dirigentes da Colônia e da Metrópole. Nesse período, havia, por um lado, concentração dos meios de produção nas mãos de um pequeno grupo de "fidalgos" proprietários de terra e, por outro, um grande número de trabalhadores dependentes desse meio de produção para garantir a própria sobrevivência. Para que essa configuração político-econômica fosse mantida, postula Souza (1992), era necessária uma política educacional que possibilitasse a dependência intelectual, pelo atrofiamento de livres reflexões e pela ausência da crítica.

Assim, as políticas educacionais voltavam-se para a efetivação de uma educação formal que visava suprir e manter a relação de dependência da Colônia em relação à Metrópole, sendo que a primeira deveria fornecer reservas de vegetais e minerais para a segunda, evitando a autonomia desta em relação àquela. Conforme Severino, “[...] a impregnação ideológica ajuda a manter inalteradas as condições objetivas da existência 
(alienação objetiva) e reforça a percepção enviesada dessas condições pela consciência (alienação subjetiva).” (SEVERINO, 1986, p. 70).

Naquele contexto, o ensino de Filosofia não era autônomo, mas adaptava-se ao modelo de formação que se esperava da escola, contribuindo para manter o poder nas mãos da monarquia, contribuindo para a manutenção da estrutura social que vigorava nesse período.

\section{O Ensino de Filosofia a partir da Reforma Pombalina}

A disseminação das ideias iluministas no Brasil Colônia começa a transformar a concepção educacional influenciada pelo pensamento tomista. A Reforma Pombalina, ocorrida a partir de 1759, ano em que os jesuítas foram expulsos do Brasil, representou o marco da superação dessa concepção religiosa de educação, atribuindo ao Estado a responsabilidade pela instrução pública. Essa nova política educacional era inspirada nos ideais iluministas, sem romper de forma definitiva sua ligação com a Igreja, pois naquele período o Império Português ainda era unido à Igreja pela política do padroado.

Severino (1986) propala que a Reforma Pombalina não representou o fim do pensamento escolástico no Brasil, pois até nos dias atuais esse pensamento medeia a relação de muitas pessoas com a realidade. Contudo, naquele período o ensino de Filosofia por razões da sua própria natureza não se vincula à necessidade iluminista de explicar o mundo por meio da observação e da experimentação e, assim, começa ser desvalorizado na formação secundária. Isso fazia com que fossem abominadas as obras filosóficas dos antigos, de modo particular as de Aristóteles e as de Tomas de Aquino. As grandes revoluções científicas da modernidade, originadas pelas novas necessidades produzidas pela mudança do homem em seu modo de produzir a existência, sob a forma do capitalismo industrial, colocam-no em um novo lugar em relação ao cosmos, modificando, assim, a sua forma de pensar o mundo e de produzir conhecimento.

Com base no exposto, podemos considerar que, nesse período, por não atender às novas necessidades materiais imediatas da sociedade, tal como fazem as ciências físicas e naturais, o ensino de Filosofia fica mais voltado à formação do bacharel com a finalidade de suprir "[...] os quadros políticos e administrativos para burocracia estatal" (LIMA, 2005, p. 22). 
Por meio do contato com a ciência experimental moderna, os novos professores "leigos, filhos de proprietários rurais" (HORN, 2002, p. 21), substituem a organicidade, a sistematicidade, a linearidade curricular, a especificidade dos métodos e dos materiais e a organização progressiva do ensino, presentes no modelo jesuítico, por aulas de disciplinas isoladas. Nessa organização, o indivíduo deveria ser instruído mediante os conhecimentos das ciências naturais. Contudo, o ensino de Filosofia, oferecido a uma pequena parcela da sociedade, continua nos moldes da escolástica.

Nesse contexto, que se estenderá até a Primeira República, a escolha dos conteúdos a serem ensinados tem como critério a sua relação com a lógica e a ética, sendo "[...] esta última quase sempre sob o título - e enfoque "moral"” (HORN, 2002, p. 24). Desse modo, a intenção com o ensino de Filosofia, após o advento do estado laico brasileiro no século XIX, era o de formar não mais o "bom cristão", mas o "bom cidadão".

Isso ficou mais evidente com a Proclamação da República, em 1889, quando, "[...] sob a influência de Filosofia liberal-positivista, o ensino escolar passa a ser um veículo para disseminar os princípios e os valores do novo modelo econômico e político [...]” (LIMA, 2005, p. 23), acreditando-se que a educação ajudaria a resolver os problemas sociais do país. Nesse período são instituídas disciplinas de cunho científico nos currículos escolares, em razão da ênfase atribuída às ciências pela modernidade, reduzindo a Filosofia às humanidades literárias.

As constatações sobre a presença e a ausência da Filosofia até aqui apresentadas reforçam a ideia de que, no interior das políticas educacionais, sua inclusão ou exclusão nos currículos escolares depende da importância que a elite econômica lhe atribui no desenho econômico, político e social que esboçam para manter as estruturas sociais que estão postas.

Lima (2005), analisando as reformas educacionais posteriores à Reforma Pombalina como a reforma de Epitácio Pessoa (1901), a Rivadávia Corrêa (1911) e a Gustavo Capanema (1942), destaca uma inconstância acerca da Filosofia como componente curricular, constando que, quando presente, seu ensino manteve-se enciclopédico, elitista, transmissivo e assimilativo. A Filosofia como componente curricular ainda parecia seguir a orientação escolástica de contribuir com a formação de um indivíduo moral, estando predestinada a auxiliar o desenvolvimento de um comportamento moral diante das adversidades sociais como a falta de trabalho, a 
violência e outras que fazem parte de uma sociedade que sobrevive à custa de "relações de exploração" (SAVIANI, 2005, p. 19).

\section{O Ensino de Filosofia no período pós-guerra}

Posteriormente à Segunda Guerra Mundial, o período compreendido pela história político-econômica como o de pós-guerra ou da guerra fria, o mundo ficou polarizado em dois blocos: o capitalista, representado pelos Estados Unidos da América, e o bloco socialista, representado pela ex-União Soviética. Nessa época, foi instalado no Brasil um regime político ditatorial, controlado pelos militares e apoiado pelas potências capitalistas, com a intenção de proteger o país dos ideais socialistas, abafar a movimentação política e consolidar a inserção do país no "capital multinacional" (SHIROMA; MORAES; EVANGELISTA, 2007, p. 28). Nesse contexto, a Filosofia foi afastada dos currículos dos cursos secundários de forma gradativa, permanecendo como uma disciplina optativa dos currículos escolares (ALVES, 2002). Nesse período, houve o cerceamento da crítica, da liberdade de expressão e de pensamento. O fato de essa área do conhecimento requerer as capacidades de reflexão e de crítica sobre a realidade por meio de um pensamento livre foi um dos motivos pelos quais ela foi retirada dos currículos escolares.

A esse motivo de exclusão da Filosofia, somou-se a outro vindo diretamente das demandas do setor produtivo com as novas configurações da produção capitalista, após a segunda guerra mundial. Conforme Coriat (1985), os limites da rigidez de modelos de produção taylorista/fordista foram revelados diante das novas necessidades que surgiam. Para Harvey (1992), um dos efeitos do período pós-guerra foi o fato de se perceber que os indivíduos com pouca qualificação poderiam realizar tarefas sozinhos, obtendo, assim, maior desempenho. Isso ocorreu devido à falta de trabalhadores especializados para atender à demanda gerada pelo setor industrial.

Nessa perspectiva, a partir de 1960, de acordo com Coriat (1985) e Harvey (1992), tem início uma intensa mudança na configuração do modo de produção capitalista, marcada pela passagem do modelo rígido de produção instituída por Taylor e Ford para o modo de acumulação flexível.

A acumulação flexível, na concepção de Harvey, 
[...] envolve rápidas mudanças nos padrões de desenvolvimento desigual, tanto entre setores como entre regiões geográficas, criando, por exemplo, um vasto movimento no emprego no chamado 'setor de serviços', bem como conjuntos industriais completamente novos em regiões até então subdesenvolvidas [...] (HARVEY, 1992, p. 140).

A acumulação flexível coloca-se contrária à subdivisão do trabalho, requerendo um trabalhador polivalente e flexível às mudanças que podem ocorrer no mundo do trabalho. Harvey (1992) argumenta que na flexibilização do modo de produção ocorre o aumento da competição entre os indivíduos pelos postos de trabalho, porque um mesmo trabalhador pode desenvolver diferentes tarefas em um mesmo setor de produção. Assim,

No contexto da produção da acumulação flexível observam-se: o desemprego estrutural; o aumento da competição; a exigência de novas habilidades, ao mesmo tempo em que as outras desaparecem ou ficam obsoletas [...] (GALUCH; PALANGANA, 2008, p. 79).

Shiroma et al. (2007) propalam que é para sobreviver à crise econômica internacional - “[...] estagflação, aumento do preço do petróleo, crise fiscal do estado [...]" (SHIROMA; MORAES; EVANGELISTA, 2007, p. 35) - que o capital sofre uma mudança no modo de sua organização. Essa mudança refere-se à passagem do modelo rígido da produção taylorismo/fordismo para o toyotismo - modelo flexível à demanda do mercado.

Nesse contexto de reestruturação do capital, a Filosofia foi retirada dos currículos das escolas públicas brasileiras pela publicação da lei 5.692, de 1971. Com essa lei, se instaura de modo oficial a educação tecnicista no Brasil. Com isso, as políticas educacionais atendem a necessidade de profissionalizar os estudantes das escolas públicas para que fossem atendidas as novas demandas do sistema econômico, de modo a impulsionar o desenvolvimento da economia. Pregava-se que quanto mais especializado fosse o indivíduo, maior seria a sua garantia de pleno emprego.

Considerando-se que a educação era pensada sob o ponto de vista do pragmatismo, não se vê motivos para que a Filosofia continuasse ocupando um lugar no currículo escolar. O que se pretendia nesses níveis de ensino era qualificar os trabalhadores para atender às novas exigências do mercado de trabalho, haja vista que nesse período a educação era entendida “[...] como tendo por função preparar as pessoas para atuar num mercado em expansão que exigia força de trabalho educada. À escola cabia formar a mão-de-obra que progressivamente seria incorporada pelo mercado [...]" (SAVIANI, 2005, p. 21). 
A Filosofia foi acusada de não atender aos interesses econômicos, ideológicos e políticos do momento, que se reconfiguravam sob os princípios da acumulação flexível. Esse fato dispensava o trabalhador da capacidade de reflexão e crítica da realidade e valorizava a polivalência e adaptação do sujeito às mudanças do capital. Dessa maneira, esse seria outro elemento que, de forma relacionada à acusação feita à Filosofia pelos militares, de ameaçadora da ordem política social do país, retirou o seu ensino dos currículos escolares.

Com a Filosofia retirada dos currículos, em seu lugar foi inserida, de forma obrigatória, a disciplina de Educação Moral e Cívica, a qual se constituirá no currículo escolar em um meio de formar o estudante brasileiro tendo em vista a Doutrina de Segurança Nacional. A partir das afirmativas sobre a reorganização do capital no período pós-guerra, acredita-se que o menos desejado era que o trabalhador realizasse reflexões acerca da sua condição humana, que refletisse sobre e analisasse a sua ação prática no mundo. A falta de reflexão e de análise por parte do trabalhador, sobre a sua condição humana, manteria a sua compreensão no nível da experiência cotidiana. Acreditamos que a Filosofia, pelo seu potencial crítico e reflexivo, poderia ser um empecilho para que a sociedade avançasse nos novos rumos definidos pelo capital.

\section{O Ensino de Filosofia no período de redemocratização do país: em busca da criticidade}

A ausência da Filosofia nos currículos escolares na década de 1970 não foi aceita passivamente e o período foi marcado por mobilizações em prol do retorno da Filosofia às salas de aula.

Em meados de 1970, teve início

[...] uma luta pela reversão do processo de extinção, e o primeiro passo se dá com a criação do Centro de Atividades Filosóficas, mais tarde, transmutando-se a sua denominação para Sociedade de Estudos e Atividades Filosóficos (SEAF) (LIMA, 2005, p. 25).

Essa Sociedade tinha por objetivo criar um espaço de debate sobre a volta da Filosofia aos currículos, discutindo também os conteúdos e as formas de ensiná-los. Carminat (1997) informa que a SEAF contribuiu para fortalecer as discussões sobre o ensino de Filosofia em vários pontos do país, apostando em uma Filosofia como instrumento para a crítica. 
Vale lembrar que, em 1980, “[...] também se fortaleceram e irromperam intensos movimentos sociais marcados pela autonomia e contestação à ordem estabelecida [...]" (LIMA, 2005, p. 30), como o movimento dos operários, bancários, professores e petroleiros. Paralelamente às mobilizações trabalhistas, intensificam-se as discussões acerca da volta da obrigatoriedade do ensino de Filosofia e da Sociologia aos currículos escolares em encontros, seminários, reuniões em nível regional e nacional.

Temos aqui uma situação que deve ser observada: a relação entre o período de redemocratização em que o Brasil vinha passando e a necessidade de ensinar uma Filosofia Crítica. A formação escolar para a parcela da sociedade contrária ao capital parece estar voltada à formação de um pensamento crítico com base no qual o indivíduo consiga refletir e analisar o mundo que o cerca, reconhecendo as contradições do regime ditatorial imposto pelo golpe militar de 1964. Isso pode ser observado, de acordo com Lima (2005), em uma das reuniões da SEAF:

[...] a Filosofia é 'uma disciplina normativa imprescindível para proporcionar ao aluno um raciocínio metódico, sustentado num repertório cultural humanístico, que lhe permita compreender o mundo que o cerca' (NIELSEN NETO, 1986, p.13, apud LIMA, 2005, p. 27).

Conforme o exposto, percebemos indícios históricos da preocupação com a metodologia, os conteúdos que deveriam ser ensinados e as capacidades humanas que deveriam ser desenvolvidas mediante o ensino dessa área do conhecimento. Considerase que a promoção da crítica ocorre, segundo Nielsen Neto (1986), caso o aluno receba na escola "[...] instrumentos intelectuais capazes de proporcionar-lhe nova visão histórica, quando a realidade que o cerca se modifica" (NIELSEN NETO, 1986, p.14, apud LIMA, 2005, p. 27). Nesse sentido, completa: “[...] não é transformando a aula em assembleia que obteremos alunos participantes" (NIELSEN NETO, 1986, p. 14, apud LIMA, 2005, p. 27).

A postura de Nielsen Neto (1986) reflete o modo de pensar dos contrários ao governo militar. Essa nova postura mudaria a trajetória do ensino de Filosofia no Brasil, de um ensino enciclopédico, que visava à memorização dos conteúdos, para um ensino que instrumentalizasse o aluno para a crítica social. Nesse momento, em termos legais, havia uma orientação sobre a importância do ensino de Filosofia nos cursos de $2^{\circ}$ grau, atual Ensino Médio, mas não a tornava obrigatória no currículo escolar desse nível de ensino. 


\section{O Ensino de Filosofia em um contexto neoliberal}

O contexto de reestruturação do capitalismo, conhecido como neoliberalismo, exigiu um processo de intensa mudança para atender às exigências apresentadas pelo capital. O Ensino Médio brasileiro, em meados da década de 1980, passou por um novo processo de reformulação.

Nesse contexto, iniciam-se os debates para a construção da nova Lei de Diretrizes e Bases da Educação. Essa nova Lei traz de volta a obrigatoriedade de Filosofia nos currículos escolares. Destarte, seus princípios gerais foram influenciados pelas exigências do novo modelo de produção capitalista, tanto em relação ao conteúdo quanto no que se refere a sua contribuição na formação do indivíduo. Isso pode ser verificado, segundo Mendes, no embate entre os segmentos que se organizaram para a elaboração da atual Lei de Diretrizes e Bases da Educação Nacional (LDB).

De acordo com Mendes,

Efetivamente, o embate se deu entre o segmento de iniciativa popular, com projeto que propunha uma LBD voltada para os interesses da escola pública, e um projeto de iniciativa dos representantes políticos do capital, que propunha uma LDB voltada para os interesses da iniciativa privada e defensores dos interesses do capital internacional globalizado (MENDES, 2008, p. 35).

A nova LDB, Lei $\mathrm{n}^{\circ}$. 9394/96, foi aprovada em um contexto de intensa reestruturação da economia brasileira pelo viés do neoliberalismo. E, dos dois projetos apresentados, um voltado à escola pública e outro para os interesses da iniciativa privada, venceu o segundo, contemplando os anseios dos representantes políticos do capital e da economia internacional. Na educação, tal reestruturação implicou passar

[...] para uma lógica econômica estritamente privada e guiada pela ênfase nas capacidades e competências que cada pessoa deve adquirir no mercado educacional para atingir uma melhor posição no mercado de trabalho (GENTILI, 2002, p. 51).

Diferente da crença de que a escola prepararia os indivíduos para ocuparem determinadas vagas no mercado de trabalho, como se a formação profissional fosse sinônimo de "pleno emprego", passa a vigorar a ideia de que será o próprio indivíduo, pela sua constante capacitação profissional, quem abrirá a possibilidade para que ocupe um posto de trabalho. Nesse contexto, o indivíduo passa a ser responsabilizado pelo seu 
desemprego e a escola supostamente oferecerá os meios que permitirão ao indivíduo disputar vagas no mercado de trabalho (SAVIANI, 2005).

Mendes (2008) assinala que o ponto forte do discurso governamental era a assertiva de que o Brasil era um país defasado economicamente em relação às grandes potências capitalistas como os Estados Unidos da América, Inglaterra, Alemanha e França, e assim, justificava-se a necessidade de serem feitos alguns ajustes para que o país pudesse estar em consonância com a ordem do mercado mundial. A reforma na educação era um dos alvos para que, de acordo com o governo do então presidente do Brasil, Fernando Henrique Cardoso (1995-2002), acontecesse uma reestruturação da economia brasileira dentro da nova ordem econômica.

Reestruturar a economia no interior dessa nova ordem consistia em primeiramente conceber um Estado sem lutas de classes e menosprezar todas as compreensões político-sociais que concebessem a existência de uma sociedade dividida em classes e a necessidade de torná-la igualitária.

Um documento que influenciou de modo mais significativo a elaboração da atual LDB, que acabou, conforme Mendes (2008), representando os novos interesses do modo de produção capitalista em relação à educação, foi o Relatório Jacques Delors. Intitulado como Educação: um tesouro a descobrir, esse relatório foi elaborado para responder às exigências do mundo capitalista do final do século XX. Foi produzido e organizado pela Organização das Nações Unidas para a Educação, a Ciência e a Cultura (UNESCO), Fundo das Nações Unidas para a Infância (UNICEF), Programa das Nações Unidas para o Desenvolvimento (PNUD) e o Banco Mundial. Os pressupostos nele presentes subsidiaram as políticas educacionais nos países chamados, pelas potências capitalistas, de "países em desenvolvimento", dentre eles, o Brasil. Esse documento foi publicado no Brasil por meio de uma parceria entre a UNESCO e o Ministério da Educação (MEC).

A reforma educacional sinalizada como necessária pelo Relatório Jacques Delors visava a atender aos interesses do capital e deveria por em prática uma educação fundada nos princípios da qualificação para o trabalho e para exercício da cidadania, com o objetivo de levar o indivíduo a prezar por aspirações que fossem comuns a todos. Isso ocorreria mediante uma educação escolar que desenvolvesse nos indivíduos a vontade de viver juntos, despertasse em cada pessoa os princípios da solidariedade, do espírito de ajuda mútua e da criatividade, na intenção de formar um indivíduo capaz de viver em um mundo complexo e dinâmico, tornando-o sensível e flexível às constantes 
mudanças ocorridas na sociedade, advindas das transformações que ocorressem no curso da economia mundial e, consequentemente, no mundo do trabalho. Dessa maneira, a intenção era formar "[...] para a inovação pessoas capazes de evoluir, de se adaptar a um mundo em rápida mudança e capazes de dominar essas transformações" (DELORS, 1996, p. 72).

A educação passa a ser vista pelos defensores do capital como uma das responsáveis pela defasagem econômica brasileira em relação às grandes potências capitalistas. Para esses defensores, o mau gerenciamento educacional levou aos grandes índices de exclusão, que segundo o governo de Fernando Henrique Cardoso, podiam ser percebidos pelas altas taxas de repetência e evasão.

Apesar da forte influência externa na elaboração da nova LDB, havia também demandas internas que precisavam ser contempladas no jogo de forças que se instaura nesse momento. Assim, oficializou-se a obrigatoriedade do ensino dos conteúdos de Filosofia e de Sociologia no Ensino Médio. A importância e a função da Filosofia foram apresentadas nessa Lei, de forma indireta no Artigo 35, pelo qual se afirma ser necessário, na formação escolar, "o aprimoramento do educando, incluindo a formação ética e o desenvolvimento da autonomia intelectual e do pensamento crítico" (inciso III). Já no Artigo 36, parágrafo $1^{\circ}$, inciso III, consta que o papel da Filosofia na Educação Básica é abordado de forma mais direta ao ser feita a referência ao "domínio dos conhecimentos de Filosofia e de Sociologia" como "necessários ao exercício da cidadania".

Para atender às reivindicações dos diversos movimentos ocorridos no país e às novas necessidades econômicas, a atual LDB tornou obrigatória a Filosofia como conteúdo curricular, mas seu conteúdo e objetivo são readequados à perspectiva de formação assumida pelos organismos internacionais, vinculando-os ao ensino de valores morais, com a função de desenvolver nos indivíduos os laços de solidariedade, cooperação, respeito às diferenças, tentando agregar o que o capital desagrega. Ao finalizar o Capítulo 2 do Relatório Delors, intitulado "Da Coesão Social à Participação Democrática", são apresentadas as "dicas e recomendações" para a educação. Dentre elas o novo entendimento do que seja o papel da escola e das relações humanas almejadas:

A educação não pode, por si só, resolver os problemas postos pela ruptura (onde for o caso) dos laços sociais. Espera-se, no entanto, que contribua para o desenvolvimento do querer viver juntos, elemento 
básico da coesão social e da identidade nacional (DELORS, 1996, p. 59).

Nesse contexto, a Filosofia é aceita por ser considerada importante para a formação do indivíduo capaz de trabalhar de forma cooperativa, com vistas ao aumento da produtividade ou até mesmo para "combater o egoísmo excessivo". Enfim, diante da necessidade do capital de manter a harmonia social por meio do "aprender a viver juntos", mesmo quando os laços sociais estão rompidos, é transferida "parte dessa tarefa para o sistema educacional” (LEONEL, 2007, p. 57), com a intenção de "apaziguar as diferenças econômicas, sociais, raciais e culturais" (SFORNI, 2004, p. 76) existentes na sociedade.

\section{Considerações finais}

Por meio do estudo realizado, chegamos à conclusão de que as políticas públicas educacionais que mantiveram ou retiraram a Filosofia dos currículos escolares foram respostas às necessidades de estruturação ou reestruturação do capital ao longo da história da educação brasileira, buscando a constituição de uma educação que torna o indivíduo adaptável às exigências desse modo de produção.

Nesse sentido, o desenvolvimento previsto para o indivíduo estaria centrado em capacidades que atendessem às exigências do sistema econômico. A presença da Filosofia na escola só era defendida pelos órgãos oficiais que definiam as políticas públicas educacionais quando considerada capaz de contribuir de alguma forma com as exigências de formação gestadas no interior do sistema econômico.

Cabe, porém, destacar, que essas determinações nem sempre foram aceitas com passividade, elas foram motivo de resistência e tensões na área. Outras perspectivas de formação eram discutidas nas escolas e no meio acadêmico, o que foi favorável para a organização dos profissionais da área. A defesa da SEAF - Sociedade de Estudos e Atividades Filosóficas - de que a Filosofia deveria proporcionar ao aluno, com base na leitura de textos clássicos, o desenvolvimento de uma reflexão rigorosa comprometida com a transformação da realidade, mesmo que não tenha sido assumido pelas políticas públicas como norteadora de seus encaminhamentos, permanece viva no horizonte de 
lutas quando se tem como objetivo um ensino de Filosofia comprometido com o desenvolvimento integral do ser humano.

\section{REFERÊNCIAS}

ALVES, D. J. A Filosofia no Ensino Médio: ambiguidades e contradições na LDB. Campinas: Autores associados, 2002.

Brasil. Lei n⿳0 9.394, de 20 de dezembro de 1996. Estabelece as diretrizes e bases da educação nacional. Diário Oficial da União, 23 dez. 1996.

CARMINATI, C. J. O ensino de Filosofia no II grau: do seu afastamento ao movimento pela sua reintrodução (A Sociedade de Estudos e Atividades Filosóficos SEAF). 1997. 195f. Dissertação (Mestrado em Educação) - Educação, Universidade Federal de Santa Catarina, Florianópolis, Santa Catarina, 1997.

CORIAT, B. O. Taylorismo e a Expropriação do Saber Operário. In: PIMENTEL, Duarte et al. (Orgs.). Sociologia do Trabalho. Lisboa: A regra do jogo, 1985.

DELORS, J. et al. Educação um tesouro a descobrir. Relatório para a Unesco da comissão internacional sobre a educação para o século XXI. São Paulo: Cortez; Brasília, DF: MEC: UNESCO, 1996.

GALUCH, M. T. B.; PALANGANA, I. C. Experiência, Cultura e Formação no Contexto das Relações de Produção Capitalistas. Intermeio (UFMS), v. 14, n. 28, p. 71-87, 2008. Disponível em:

<http://www.intermeio.ufms.br/revistas/intermeio28.html > . Acesso em 20: dez. 2012.

GENTILI, P. Três teses sobre a relação trabalho e educação em tempos neoliberais. In: LOMBARDI, J.C., SAVIANI, D. e SANFELICE, J.L. (Orgs.), Capitalismo, trabalho e educação. Campinas: Autores Associados, 2002, p. 45-59.

HARVEY, D. Condição Pós-Moderna: uma pesquisa sobre as origens da mudança cultural. São Paulo: Loyola, 1992.

HORN, G. B. Por uma mediação praxiológica do saber filosófico no Ensino Médio: análise e proposição a partir da experiência paranaense. 2002. 275f. Tese (Doutorado em Educação) - Faculdade de Educação, Universidade de São Paulo, São Paulo, 2002.

LEONEL, Z. Tendência atual da História da Educação. In: Educação em Debate: perspectivas, abordagens e historiografia. Campinas: Autores associados, 2007, p. 5372.

LIMA, M. A. C. A prática de ensino de Filosofia num contexto de reestruturação capitalista: construção de uma experiência problematizadora com o ensino. 2005. $240 \mathrm{f}$. 
Tese (Doutorado em Educação) - Programa de Pós-graduação em Educação,

Universidade Federal de Minas Gerais, Belo Horizonte, Minas Gerais, 2005.

MENDES, A. A. P. A construção do lugar da Filosofia no currículo do Ensino

Médio: análise a partir da compreensão dos professores de Filosofia da escola pública paranaense. 2008. 163f. Dissertação (Mestrado em Educação) - Programa de Pósgraduação em Educação, Universidade Federal do Paraná, Paraná, Curitiba, 2008.

SAVIANI, D. As concepções pedagógicas na história da educação brasileira. 2005. Disponível em: <http://www.histedbr.fae.unicamp.br>. Acesso em: 18 jan. 2011.

SEVERINO, A. J. Educação, Ideologia e Contra-Ideologia. São Paulo: EPU, 1986.

SFORNI, M. S. de F. Aprendizagem conceitual e organização do ensino:

contribuições da teoria da atividade. Araraquara: Junqueira \& Marin Editora, 2004.

SHIROMA, E. O.; MORAES, M. C. M. de; EVANGELISTA, O. Política educacional. Rio de Janeiro: Lamparina, 2007.

SOUZA, S. M. R. Por que Filosofia? Uma abordagem histórico-didática do ensino de Filosofia no $2^{\circ}$ grau. 1992. 225f. Tese (Doutorado em Educação) - Faculdade de Educação, Universidade de São Paulo, São Paulo, 1992.

\section{Como referenciar este artigo}

SFORNI, Marta Sueli de Faria.; BELIERI, Cleder Mariano. Necessidades produtivas e exigências de formação: a filosofia no ensino médio. Revista Ibero-Americana de Estudos em Educação, Araraquara, v. 11, n. 4, p. 2030-2045, 2016. Disponível em: <http://dx.doi.org/10.21723/riaee.v11.n4.7782>. E-ISSN: 1982-5587.

Submissão em: setembro/2015

Aprovação final em: novembro/2016 